\title{
Nadir Görülen Kartagener Sendromlu Bir Olgu
}

\author{
A Rare Case of Kartagener's Syndrome
}

\author{
Mehmet Fatih ELVERİ̧̧LI \\ (C) 0000-0002-5103-4089 \\ PInar YILDIZ GÜLHAN \\ (B) 0000-0002-5347-2365 \\ Şule YILDIZ \\ (i) 0000-0002-2069-8202 \\ Ege GÜLEÇ BALBAY \\ (10) 0000-0002-1557-7019
}

Düzce Üniversitesi Tıp Fakültesi Gögüs Hastalıkları AD, Düzce

\begin{abstract}
ÖZ
Kartegener sendromu bronşiektazi, kronik sinüzit ve situs inversus triadı ile karakterize olan otozomal resesif geçişli, yaklaşık 30000 canlı doğumda bir görülen nadir bir hastalıktır. Elektron mikroskopik görüntülemede görülen en sık bozukluk, epitelyal silyalarda dynein kollarının yokluğudur. $\mathrm{Bu}$ hastalıkta siliyal aktivitenin bozulması nedeniyle aşırı balgam birikmesi görülür. Hastalığın tedavisi semptomlara yöneliktir. İnfertilite ve sağırlık görülebilir. Kartagener sendromunun uyku kalitesini düşürdüğü de görülmüştür. Hastaların enfeksiyonlardan korunması için gögüs fizyoterapisi, influenza ve pnömokok aşılarının yapılması önerilir. Bu hastaların toz, duman gibi partikül içeren gazlardan uzak durmaları gerekmektedir. Bu çalışmada, sık hastane başvurusuna rağmen geç tanı konulan, obstrüktif uyku apne sendromu ile birliktelik gösteren 33 yaşında erkek olgu klinik ve radyolojik bulgular ile sunuldu.
\end{abstract}

Anahtar kelimeler: Kartagener sendrom; obstrüktif uyku apne; primer silier diskinezi.

\begin{abstract}
Kartagener syndrome is a rare autosomal recessive disorder seen about in one per 30000 live births and characterized by bronchiectasis, chronic sinusitis and situs inversus triad. Absence of dynein arms in epithelial cilia is the most common defect in electron microscopic examination. Extreme sputum retention is seen due to cilial disfunction in this disease. Treatment of the disease is directed to symptoms. Infertility and deafness can be seen. It has been also observed that Kartagener syndrome decreases sleep quality. In order to protect the patients from infections, chest physiotherapy, influenza and pneumococcal vaccines are recommended. These patients should stay away from particulate included gases such as dust and smoke. In this study, a 33 year old male patient diagnosed late despite frequent hospital admissions, coexistence with obstructive sleep apnea syndrome was presented with clinical and radiological findings.

Keywords: Kartagener syndrome; obstructive sleep apnea; primary ciliary dyskinesia.
\end{abstract}

\section{GíRiș}

Bronşiektazi, situs inversus ve sinüzit tiradından oluşan kartagener sendromu ilk olarak 1933 yılında Kartagener tarafindan tanımlanmıştır (1). Primer siliyer diskinezi (PSD) sendromlarının yarısını oluşturan bu hastalık otozomal resesif geçiş gösterir (2). 1/15.000-1/30.000 siklıkla görülen nadir bir hastalıktır. Epitelyal silialarda dynein kollarının yokluğu elektron mikroskopik incelemede en sık görülen ultrastrüktürel bozukluk olup, olguların bir kısmında ise hareketli, fakat işlevsel olmayan silia işlevi gözlemlenmiştir (3). Bu çalışmada infertilite ve solunum semptomları ile hastaneye sık başvurusu olmasına rağmen geç tanı konulmuş Kartagener Sendromlu olgu sunulmuştur.

\section{OLGU SUNUMU}

Otuz üç yaşında erkek hasta Göğüs Hastalıkları polikliniğine öksürük ve pürülan balgam şikayetinde artış olması nedeniyle başvurdu. Mesleği şoförlük olan hasta Kabul Tarihi / Accepted : 17.04.2019 Çevrimiçi Yayın Tarihi / sigara kullanmayıp pasif maruziyet öyküsü mevcuttu. Yedi yıldır evli ancak çocuk 
sahibi değildi. Hastanın öz geçmişinde çocukluk çağından beri sık kulak ve alt solunum yolu enfeksiyonu geçirme öyküsü mevcuttu. İki yıl önce infertilite nedeniyle tedavi görmüş ancak başarılı olunamamıştı. Fizik muayenede solunum seslerinde uzama mevcuttu. Kalp tepe atımı sağ midklavikuler hatta, 4. interkostal aralıkta alındı. Tansiyon arteryel 120/84 mm/Hg, nabız 75/dakika, ateş $36.8^{\circ} \mathrm{C}$ idi. Laboratuvar tetkiklerinde C-reaktif protein $15 \mathrm{mg} / \mathrm{dL}$ lökosit 19.100/mm3 idi. Nonspesifik balgam kültüründe üreme olmadı, üç balgam örneğinde aside rezistan basil negatif saptand. Biyokimyasal tetkikleri normal sinırlardayd1. Solunum Fonksiyon Testinde (SFT), zorlu vital kapasite (FVC) \%84 (4140 ml), birinci saniyedeki zorlu ekspiratuvar volüm (FEV1) \%65 (2690 ml), FEV1/FVC \%64, zirve akım hızı (PEF) \%61 (5850 ml) ve MEF25-75 ise \%28 olarak ölçüldü. Ekokardiyografisinde dekstrokardisi mevcuttu. Ejeksiyon fraksiyonu \%60 olarak bulundu. Posterior anterior akciğer grafisinde dekstrokardisi izlenen hastanın (Resim 1), kontrastlı bilgisayarlı toraks tomografisinde situs inversus, her iki akciğerde yer yer tübüler ve kistik bronşiektazik alanlar izlenmekteydi (Resim 2). Panazal sinüs tomografisinde nazal polipozis maksiller sinüste enfekte proçes izlendi (Resim 3). Horlama, tanıklı apne ve gündüz aşırı uykululuk şikayetleri olan hastaya yapılan Polisomnografi (PSG) tetkikinde apne-hipopne indeksi 15,8 olarak bulundu. Hastaya orta derece Obstrüktif Uyku Apne Sendromu (OUAS) tanısı konuldu. Çocukluk çağında sık kulak yolu enfeksiyonu geçirme öyküsü olan hastanın işitme azlığı şikayeti olması üzerine yapılan Kulak Burun Boğaz muayenesinde her iki dış kulak yolu ve zarları doğal, yapılan odyometride sağda $23 \mathrm{db}$, solda $37 \mathrm{db}$ işitme kaybı saptand1.

\section{TARTIŞMA}

1933 tarihinde Kartagener kendi adı ile adlandırdığı, sinüzit, bronşektazi ve situs inversus triadı ile giden bir sendrom tanımlamıştır (1). Bu sendromda sağırlık ve infertilite de görülebilmektedir (4). Bizim olgumuz ve eşinde infertilite nedeniyle in vitro fertilizasyon denenmiş ancak sonuç alınamamıştır. Çocukluk çağında sık otit geçirme öyküsü olup yapılan odyometri testinde her iki kulakta işitme kaybı saptanmıştı. Kartagener sendromunda kronik ve rekürren gelişen enfeksiyonlar erken erişkinlik yıllarında bronşiektazi gelişimine neden olabilmektedir $(5,6)$. Çocukluk çağından beri s1k otit, sinopulmoner enfeksiyon geçiren hastamızda bilateral minimal tübüler bronşiektazi ve solda santral kistik bronşiektazi izlenmekteydi. SFT normal olabilir veya obstrüktif tipte solunum fonksiyon testi bozukluğu görülebilir (7). Bizim olgumuzda SFT'de orta derece obstrüksiyonu olup hastaya bronkodilatatör tedavi başlandı. Hastalığın tanısı sıklıkla normal olmayan solunum sistemi epitelinin elektron mikroskopik görüntülenmesi ile konulmaktadır. Epitelyal silyalarda dynein kollarının olmaması elektron mikroskopik incelemede en sik görülen bozukluktur (8). Çocukluk çağında kronik otosinopulmoner enfeksiyon geçirenler hastalarda tarama testi olarak düşük nasal nitrik oksit seviyeleri kullanılsa da tanı koydurucu test olarak elektron mikroskopisi ve genetik testleriyle doğrulanmasına ihtiyaç duymaktadır (9). Hastanın sinüzit, bronşiektazi ve situs inversus triadını sağlamasıyla Kartagener Sendromu tanısı konuldu.

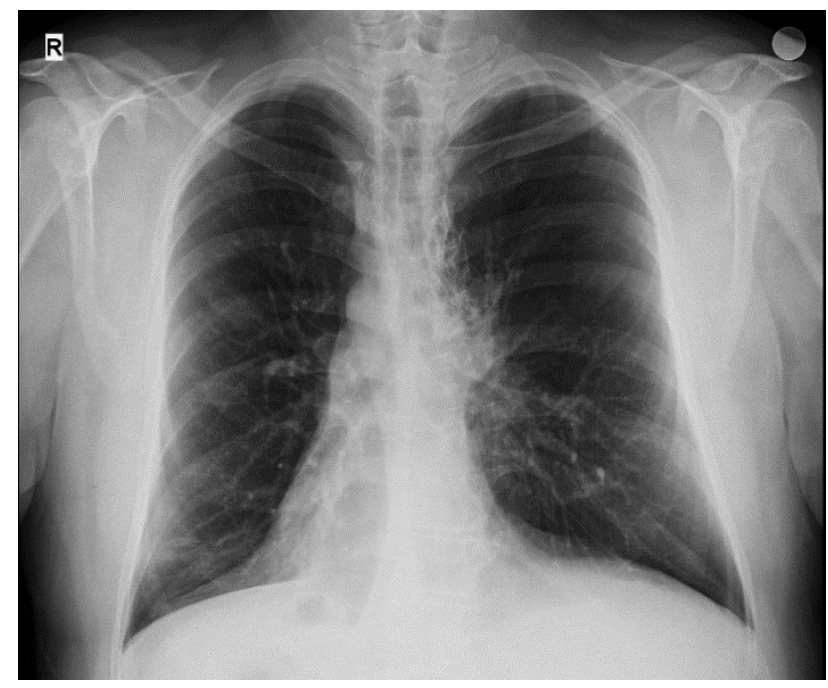

Resim 1. Posterior anterior akciğer grafisinde görülen dekstrokardi

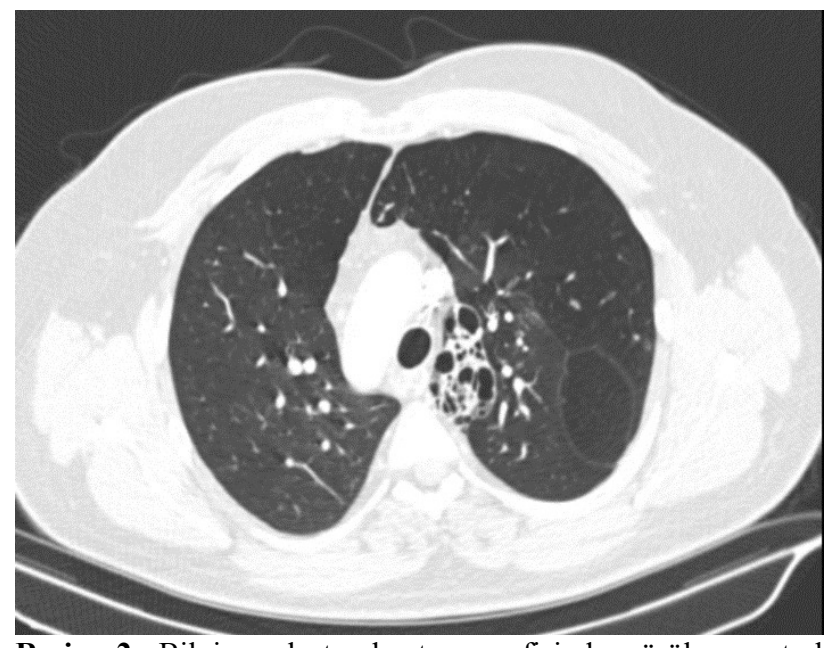

Resim 2. Bilgisayarlı toraks tomografísinde görülen santral kistik bronşiektazi

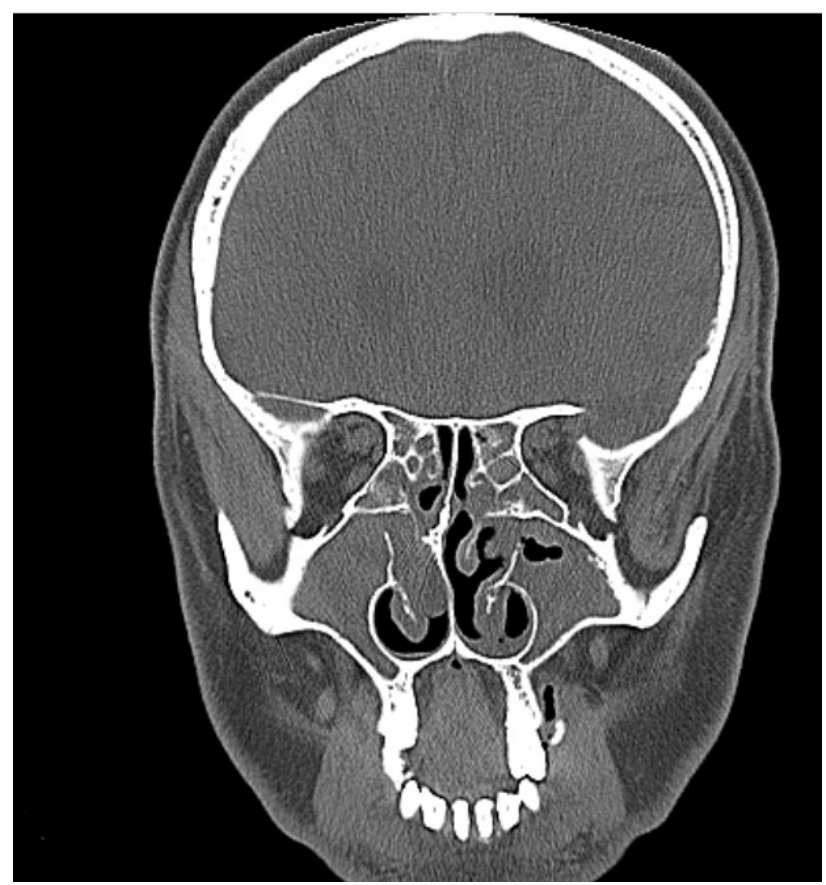

Resim 3. Paranazal sinüs tomografisinde sinüzit ile uyumlu görünüm 
Hastaların radyolojik incelemesinde havalanma artışı, bronş duvar kalınlaşmaları, segmenter volüm kaybı ve bronşiektazi görülebilir (10). Bizim olgumuzda da bronşiektazi, bronş duvar kalınlaşmaları havalanma artışı segmenter volüm kaybı mevcuttu.

PSD'li hastalarda sağlıklı insanlara göre uyku kalitesinin daha düşük ve OUAS oranlarının daha yüksek olduğu bulunmuştur (11). Oktem ve ark. (11) tarafindan yapılan 29 PSD'li olgudan oluşan bir seride 11 hastanın uyku kalitesinin kötü olduğu, hastaların \%65'inde horlama, \%52'sinde PSG ile OUAS tanısı konulduğu, sigara dumanına maruz kalanlarda horlama ve OUAS sıklığının anlamlı olarak arttığı gösterilmiştir. Bizim olgumuz da sigara kullanmamasına rağmen pasif maruziyet öyküsü olup yapılan PSG testinde orta OUAS tanısı konuldu.

Kartagener sendromu otozomal resesif geçişli olması nedeniyle aile taramalarının yapılması önerilir. İmmotil silia nedeniyle sık enfeksiyon geçiren bronşiektazi ile seyreden hastalarda gögüs fizyoterapisi faydalı olabilir. Hastaların enfeksiyondan korunması için influenza ve pnömokok aşılarının yapılması toz, duman gibi partikül içeren gazlardan uzak durmaları önerilir. $\mathrm{Bu}$ hastaların yakın takip altında olması, kültür antibiyogramın bilinmesi atak sırasında doğru antibiyotiği başlamada yardımcı olur. İnfertilite ile seyretmesi nedeniyle evlilik öncesi gerekli bilgilendirmenin yapılması önem arz etmektedir. İnfertilite tanısı olan, sık enfeksiyon geçiren hastalarda Kartegener sendromu düşünülmelidir.

\section{KAYNAKLAR}

1. Cowan MJ, Gladwin MT, Shelhamer JH. Disorders of ciliary motility. Am J Med Sci. 2001;321(1):3-10.
2. Shakya K. Kartagener syndrome: a rare genetic disorder. JNMA J Nepal Med Assoc. 2009;48(173):625.

3. Afzelius BA. Immotile cilia syndrome: past, present and prospects for the future. Thorax. 1998;53(10):8947.

4. Okutan V, Zeren H, Doğan M, Tuncer İ, Hastürk S. Kartagener sendromlu bir olgu. Türkiye Klinikleri J Med Sci. 1996;16(6):451-4.

5. Arı Yuca S, Yuca K, Özgökçe B, Yılmaz C, Avcu S. Kartagener sendromu. Selçuk Med J. 2011;27(1):34-6.

6. de Iongh RU, Rutland J. Ciliary defects in healthy subjects, bronchiectasis, and primary ciliary dyskinesia. Am J Respir Crit Care Med. 1995;151(5):1559-67.

7. Kaya A, Uğur Kaya S, Fitöz S, Tuncalı T, Gönüllü U. Kartagener sendromu: üç olgu sunumu. Toraks Dergisi. 2002;3(1):113-6.

8. Swartz MN. Bronchiectasis. In: Fishman AP, editor. Fishman's pulmonary disease and disorders. 3rd ed. Newyork: McGraw-Hill Pr; 1998. p.2045-70.

9. Shapiro AJ, Josephson M, Rosenfeld M, Yilmaz O, Davis SD, Polineni D, et al. Accuracy of nasal nitric oxide measurement as a diagnostic test for primary ciliary dyskinesia. A systematic review and metaanalysis. Ann Am Thorac Soc. 2017;14(7):1184-96.

10. Erdem LO, Erdem CZ, Tor M, Gündoğdu S. İki olgu nedeniyle kartagener sendromu. Türkiye Klinikleri J Med Sci. 2005;25(3):463-5.

11. Oktem S, Karadag B, Erdem E, Gokdemir Y, Karakoc F, Dagli E, et al. Sleep disordered breathing in patients with primary ciliary dyskinesia. Pediatr Polmonol. 2013;48(9):897-903. 